\title{
LA PERSECUCIÓN RELIGIOSA DE 1936-1939: ESTADO DE LA CUESTIÓN Y PROPUESTAS HISTORIOGRÁFICAS
}

\author{
POR
}

\author{
ÁNGRL David MARTín RUBio \\ Seminario Diocesano - Cáceres
}

\section{RESUMEN}

Uno de los factores ideológicos más importantes de la represión desencadenada en la zona republicana durante la Guerra Civil, fue la persecución religiosa. Esto explica que desde los primeros momentos hayan aparecido numerosas publicaciones alusivas al fenómeno. Pero carecemos aún de una valoración global de lo que supuso la persecución rcligiosa desencadenada en España desde 1931: no poseemos un catálogo actualizado de los sacerdotes y religiosos asesinađos y no podemos señalar un balance de la persecución en cada zona. En el presente trabajo se expone la trayectoria seguida por esta producción bibliográfica y se plantea la necesidad de emplear nuevas fuentes y de aplicar a los datos disponibles una metodología que permita el paso de lo biografico a lo cuantitativo. Se trata del avance metodológico de un estudio en proceso de realización.

\section{Abstract}

Religious persecution of 1936-1939: State of the question and historical proposals

A main factor in 1936-1939 Spanish civil war is the religious persecution. We have a lot of bibliography but not a definitive quantitative research with specification of regional differences. The author proposes that work, that he has begun. 


\section{ESTADO DE LA CUESTIÓN}

La producción bibliográfica sobre la persecución religiosa: etapas y caracterización

Uno de los factores ideológicos más importantes de la represión desencadenada en la zona republicana durante la Guerra Civil, fue la persecución religiosa que, por sus dimensiones, tanto cuantitativas como cualitativas, merece un estudio aparte a la hora de delimitar las causas que llevaron a la muerte a numerosos españoles.

Esto explica que desde el mismo 1934!' hasta la actualidad hayan venido apareciendo publicaciones en número muy elevado, aunque de desigual valor, alusivas a la persecución religiosa desencadenada en España durante aquellos años. Las diversas circunstancias tanto en la vida de la Iglesia como en la de la sociedad por las que se ha atravesado durante tan largo período así como las corrientes historiográficas imperantes, permiten describir una trayectoria que va desde los apresurados testimonios aparecidos en los primeros momentos a los recientes trabajos que ya nos permiten obtener una visión, siempre parcial aunque más definitiva, del fenómeno.

Lamentablemente esta recorrido no ha sido siempre en dirección ascendente. De hecho, es posible distinguir con claridad dos etapas que tienen como línea divisoria el libro fundamental de Antonio Montero Moreno ${ }^{2}$, con capacidad de marcar una época pero que careció de continuidad pues -durante algunos años- la investigación no siguio, como veremos, en las perspectivas abiertas por dicho trabajo.

Desde la guerra hasta 1961: Las memorias y los "martirologios"

Ya en la "Carta Colectiva del Episcopado Español" publicada en 1937, se advertía la magnitud sin precedentes alcanzada por la persecución religiosa en el año anterior

«Enjuiciando globalmente los excesos de la revolución comunista española, afirmamos que en la historia de los pueblos occidentales no se cono-

\footnotetext{
1 Uno de los primeros títulos de esta producción bibliografica acerca de la persecución religiosa en España puede ser: Asociación Católica NaCIONAL de Propagandistas de Oviedo: Asturias roja. Sacerdotes y religiosos perseguidos y asesinados (octubre 1934); Imprenta Trufero, Oviedo, 1935.

2 MONTERO MORENo, A.: Historia de la persecución religiosa en Espafia, 1936-1939; BAC, Madrid, 1961

La Iglesia en la Encrucijada

Hispania Sacra 49 (1997)
} 
ce un fenómeno igual de vesania colectiva, ni un cúmulo semejante, producido en pocas semanas, de atentados cometidos contra los derechos fundamentales de Dios, de la sociedad y de la persona humana...

Pero sobre todo la revolución fue "anticristiana». No creemos que en la historia del cristianismo y en el espacio de unas semanas se haya dado explosión semejante, en todas las formas de pensamiento, de voluntad y de pasión, del odio contra Jesucristo y su religión sagrada ...

Contamos los mártires por millares... $\left(n^{\circ} 6\right)$.»

En este contexto, es fácil entender la aparición de obras que, por la época y las circunstancias de su redacción, tienen un carácter apologético y militante - y, por tanto, no pueden ser examinadas sin precauciones- aunque tampoco hay que negar el valor documental de algunas de ellas. Ante la imposibilidad de una relación exhaustiva, pueden ser objeto de una triple clasificación:

\section{Testimonios, memorias, relatos personales...}

Cabe citar las diversas obras de supervivientes de las cárceles y la persecución publicadas meses después o ya en la posguerra. Entre ellas se encuentran varias decenas de título ${ }^{3}$ de evidente interés aunque algunas de sus apreciaciones y formas de expresión no mantengan todo su vigor en la actualidad.

Trabajos monográficos de carácter local o regional y alusiones en las historias generales de la guerra

Sin duda la más características de estas publicaciones -aunque podrían citarse otras- es la Historia de la Cruzada Española ${ }^{4}$, oficiosa, monumental y parcial historia de la guerra que ofrece datos de interés sobre el aspecto que nos ocupa especialmente en relación con lo ocurrido en los primeros meses de la guerra en algunas provincias de la zona republicana.

3 Pueden citarse: ANÓNIMO: Madrid bajo el terror, 1936-1937. Impresiones de un evadido que esivvo a punto de ser fusilado, Zaragoza, s.f.; FERNÁNDEZ ARIAS, A: La agonía de Madrid 19361937. Diario de un superviviente, Zaragoza, 1938; FRONTERIZ, L.: Seis meses bajo el terror rojo en Madrid, Ed. Senén Martín, Ávila, 1937; GARCíA ALONSO, F.: Flores de Herolsmo; Imprenta de la Gavidia, Sevilla, 1939; "PRESO 831": Del Madrid rojo (Últimos dias de la cárcel Modelo), Impr.Cerón, Cádiz, 1937; SÁNCHEZ RUEDA, E.: Un testigo presencial: Sigüenza bajo el dominio rojo, Sigüenza, s.f.; SPINOLA DE GIRONZA, A.: Dios sobre todo; Tip. Chulilla y Ángel, Madrid, 1940; etc.

4 ARRARÁs, J. (dir.): Historia de la Cruzada Española, varios tomos; Publicaciones Espafiolas, Madrid, 1939 y ss. 


\section{Publicaciones oficiales}

Fundamentalmente se trata de los informes que desde 1936 dio a conocer la Junta de Defensa Nacional de Burgos acerca de los asesinatos cometidos en diversas zonas de España $a^{5}$ En estas publicaciones, se detallan las víctimas de algunos pueblos y las circunstancias concretas de las torturas y ejecuciones, así como fotografias y valoraciones sobre la destrucción del patrimonio historico artístico conservado en iglesias y conventos. También tiene interés La dominación roja en España o "Causa General"s que recoge en catorce capítulos con sus correspondientes anexos documentales:

«Una mínima parte de la documentación y colecciones fotográficas obrantes en los archivos ocupados por las autoridades nacionales al ser liberada la que fue zona marxista asi como de aquellas declaraciones testificales de importancia prestadas ante los organismos de orden judicial ."

El apartado dedicado a la persecución religiosa contiene información sobre los asesinatos de obispos, sacerdotes y religiosos así como sobre la destrucción de edificios y objetos litúrgicos y varios testimonios acerca del ambiente antirreligioso de la zona republicana. En el anexo pueden verse diversas fotografias, reproducciones de documentos y una relación nominal de las víctimas de la provincia de Barcelona.

Por el momento en que se efectuó y la intención que la promovía es evidente que la "Causa General" es un ejemplo -en expresión de G. Jacksonde "acusación sin defensa" pero ello no impide que el conjunto de la información sea fiable ya que suele estar bien contrastada y su naturaleza es judicial. En todo caso, es evidente que el libro citado s6lo recoge un pequeño porcentaje del ingente y valiosísimo acervo documental que compone la "Causa $\mathrm{Ge}$ neral". Como venimos apuntando, el historiador podrá estar de acuerdo o no con las apreciaciones políticas y juicios de valor de estos libros, pero encontrará en ellos una imprescindible fuente de datos para la caracterización del fenómeno persecutorio.

5 Por citar alguno de ellos: Avance del informe oficial sobre los asesinatos, violaciones, incendios y demás depredaciones y violencias cometidas en algunos pueblos del mediodía de España por las hordas marxistas al servicio del llamado Gobierno de Madrid; Imp. Gavidia, Sevilla, 1936. Siguieron otros relativos a distintas regiones.

6 MINISTERto DE JUSTICIA: La dominación roja en España, Causa General instruida por el Ministerio Fiscal, Madrid, 1943.

1 Ibid. Introducción.

La Iglesia en la Encrucijada Hispania Sacra 49 (1997) 
Ya en los años posteriores, la persecución religiosa siguió siendo objeto de atención en estudios monográficos de carácter local e institucional así como en biografias y artículos periodísticos. Entre un gran número de títulos, merece citarse especialmente el martirologio de la diócesis de Cuenca ${ }^{8}$ publicado en dos volúmenes por el canónigo Sebastián Cirac Estopañán que ya había analizado la persecución en su pueblo natal, Caspe'.

Cirac desarrolla un plan de investigación, critica las fuentes y valora los testimonios para describir la situación de todos los pueblos de la diócesis de Cuenca y presentar las biografías detalladas con edad, condición social y otras circunstancias de 1.114 víctimas de la represión y persecución religiosa. Dado el interés de este trabajo, hubiera sido necesario un intento similar para el resto de Jas diócesis que, lamentablemente no se llevó a cabo, y que, por lo tanto, sigue pendiente ${ }^{10}$.

\section{La "Historia de la persecución religiosa" de A. Montero}

En 1961 tuvo lugar la aparición de la obra fundamental tantas veces citada de Antonio Montero Moreno, entonces director de la revista "Ecclesia" y hoy Arzobispo de Mérida-Badajoz. Su Historia de la persecución religiosa en España 1936-1939, sigue siendo el trabajo de síntesis más completo sobre el tema que nos ocupa, tanto por el análisis riguroso y crítico del fenómeno persecutorio desde sus orígenes, como por la abundante documentación aportada y, sobre todo, por los datos globales sobre el número de víctimas que han sido aceptados desde entonces.

El libro recibió en general una crítica elogiosa pero también fue objeto de reticencias ${ }^{11}$. En concreto, el dominico Fr. Arturo Alonso Lobo publicaba en "La Ciencia Tomista"'2 una nota crítica en la que hacía algunas consideracio-

3 Cirac EstopañâN, S.: Martirologio de Cuenca; Barcelona, 1947.

- Cirac ESTOPAÑÁN, S.: Los héroes y mártires de Caspe; Zaragoza, 1939

30 En todo caso, merecen citarse algunos de los "martirologios" elaborados en diversas dícoesis y congregaciones religiosas durante estos aftos: SEBASTIAN BANDARAN, J. y TINEO LARA, A.: La persecucion religiosa en la Archidiócesis de Sevilla; Editorial Sevillana, Sevilla, 1938; SANABRE SANROMÁ, J.: Martirologio de la Iglesia en la diócesis de Barcelona durante la persecución religiosa, 1936 1938; Barcelona, 1943; RJVERA RECio, Juan F.: La persecución religiosa en la diócesis de Toledo (1936-1939); 2 vols., Tolcdo 1945; VIDAL TUR, G.: Persecución religiosa. Provincia de Alicante (1936-1939); Tip. Suc. de Such, Serrá y cía., Alicante, 1951; ZAltonero Vivó, J.: Sacerdotes martires (Archidiocesis valentina 1936-1939); Alcoy, Marfil, 1951. Los títulos podrían multiplicarse.

11 Cfr. los artículos de RAGUER, H.; "Revue d'Histoire Ecclesiástique" 57(1962)618-630; HORNEDO, R.: "Razón y Fe" 164(1961)335-342 y QuBRA, M.: "Estudios Eclesíasticos" 39(1964)273 ss. 376

12 ALONSO LOBO, A.: "¿Se puede escribir asi la historia?" en La Ciencia Tomista 52 (1961)301- 
nes sobre esta obra con el deseo de verla mejorada en futuras ediciones que, lamentablemente, nunca se hicieron.

El autor de dicha reseña aducía en primer lugar una serie de observaciones de carácter general acerca de algunos de los criterios o pareceres expuestos por A. Montero que eran difícilmente asumibles en aquel momento:

- "Planteamiento de un falso dilema" entre la necesidad de superar aquella escisión y enterrar viejos rencores y, al mismo tiempo, no permitir que la historia se disuelva en el olvido.

- "Reticencia sospechosa" a otorgar a la contienda española el calificativo de Cruzada.

- "Asi no se escribe la historia": con este epígrafe ponía en cuestión el P. Lobo los reproches que. hacía Montero a los cronistas e historiadores que se habían ocupado con anterioridad del tema.

- "QQuién es el abogado del diablo?" con referencia a las causas de beatificación por martirio que sólo habían sido utilizadas como fuente parcialmente.

- "Sublata causa, tollitur effectus": por último se señalaba que "de la lectura de algunos capítulos de esta historia se saca la impresión de que muchos asesinatos cometidos por los rojos fueron causados por razones bastante diferentes a los que exige la naturaleza del martirio".

Como puede verse, ninguna de estas apreciaciones alteran el valor intrínseco de la obra, se trata de matizaciones de más contenido ideológico que historiográfico, por eso son de mayor interés las "anotaciones para una nueva edición corregida y aumentada" en las que Fr. Arturo Alonso señala:

- Habría que completar el apéndice documental haciendo constar la legislación dictada en materia religiosa por el bando nacional para hacer frente a las medidas persecutorias de los republicanos.

- A continuación se hace una serie de aportaciones de interés acerca de algunos de los episodios relatados por Montero que son complementados con testimonios y documentación:

- los sucesos de Gijón,

- la provincia de Santander,

- muertes de dominicos y de algunas religiosas,

- la aportación de seglares al martirologio. 
En resumen, puede decirse que la mayoría de estas "notas críticas" no ponen en cuestión lo sustancial de la obra de Montero aunque sí queda en pie la llamada que hacía el P. Lobo a la necesidad de una obra definitiva, de mayor calado, que ś́lo sería posible cuando adquirieran un grado de madurez las investigaciones parciales o los estudios monográficos históricamente ciertos. Como hemos apuntado, nadie llevó a cabo esa obra: las nuevas circunstancias por Jas que atravesó la Iglesia en los años siguientes hicieron que el libro de Montero dormitara en los estantes de las bibliotecas porque, debido a haberse agotado rápidamente la primera edición y a las reiteradas negativas a realizar otras, esta obra ha sido más citada y admirada en la distancia que realmente leída, estudiada y meditada.

\section{Desde los sesenta hasta nuestros días}

A pesar del interés demostrado hasta ahora por la persecución religiosa, un acontecimiento de alto valor simbólico, como fue la suspensión temporal del examen de las causas de beatificación de los mártires españoles decidida por Pablo VI, y las nuevas circunstancias de la Iglesia a partir del Concilio Vaticano II y de la sociedad española en los años de la transición política, actuaron como freno, "congelando" prácticamente las publicaciones relacionadascon la persecución religiosa ${ }^{13}$. Sin embargo el 29 de marzo de 1987 eran beatificadas tres carmelitas descalzas muertas en Guadalajara en los primeros momentos de la guerra y ya son doscientos veinte los mártires beatificados por Juan Pablo II $^{14}$, este nuevo contexto permitió y motivó un relanzamiento del interés por el tema y, desde entonces, son numerosos los libros ${ }^{15}$, en ocasiones, trabajos de

13 De este período sólo pueden citarse algunos libros como: ORDÓÑEZ MÁRQUEZ, J.: La apostasía de las masas y la persecución religiosa en Huelva, 1931-1936; CSIC, Madrid, 1968; CASTELLS SERRA, J.: Martirologi de l'Eglesia d'Urgell (1936-1939; La Seu d'Urgell 1975; VIOLA GONZÁLEZ, R.: El martirio de una Iglesia. Lérida-Lleida 1936-1939; Lérida, 1981.

14 Acerca de los procesos de beatificación de los mártires de la persecución religiosa en España, puede verse: CARCEL ORT1, V.: Marrires españoles del siglo XX; BAC, Madrid, 1995.

15 Por citar algunos, podemos referirnas a: CAMPO VILLEGAS, G.: Esta es nuestra sangre; Publicaciones claretianas, Madrid, 1992; EsPIAGO, F.: A la misión del cielo por el martirio. Sacerdoses y hermanos paúles mártires; Padres Paúles, Madrid, 1995; GómEZ CATÓN, F.: La lglesia de los márires en la provincia eclesiastica tarraconense. Primera parte: columnas rojas y La Iglesia de los mártires en la provincia eclesiástica tarraconense. Segunda parte: persecución; Ed. Mare nostrum, Barcelona, 1989; LALUBZA GIL, S.: Martirio de la Iglesia de Barbastro, 1936-1938, Obispado de Barbastro, Barbastro, 1989; PEÑART Y PEÑART, D.: La díbcesis de Huesca y la guerra de 1936; Huesca, 1992; SANCHEZ BAEZA, E.: La persecución religiosa en la díbcesis de Cartagena, 1931. 1939, Madrid, 1988; SUAREZ SANCHEZ, A.: Pasión y gloria de la Iglesia abulense; TAU, Ávila, 1987 y, permitase la inmodestia de la autocita, nuestro libro de reciente aparición La persecución religiosa en Extremadura durante la guerra civil (1936-1939); "Ascciación Cultural Carlos V", Badajoz, 1996. 
ocasión o biografías "de encargo" motivadas por las beatificaciones; en otros, monografias regionales o diocesanas aunque no se haya elaborado ninguna síntesis a nivel nacional ${ }^{16}$. Igualmente ha tenido lugar la reedición de alguno de los "martirologios" clásicos".

Más desigual es el trato dado a la persecución religiosa en la historiografía general sobre la guerra civil a lo largo de todos estos años. A partir de los sesenta son cada vez más frecuentes, en las obras de síntesis españolas y extranjeras, las alusiones al fenómeno represivo en ambos bandos. En las obras de $\mathrm{H}$. Thomas ${ }^{18}$ y G. Jackson ${ }^{19}$, la persecución religiosa se relaciona con la represión y, en líneas generales, esas páginas suelen consistir en un anecdotario de casos truculentos y en unos primeros intentos de caracterización que se han convertido en tópico y se vienen repitiendo hasta hoy: Thomas hace algunas apreciaciones discutibles en relación a este tema que no le impiden dar por hecho que los ataques "fueron acompañados por una matanza colosal de los miembros de la Iglesia y de la burguesía" aunque en una nota matiza cómo no solo mataron a guardias civiles, sacerdotes o industriales, sino también a innumerables obreros, tenderos, administrativos, etc. que eran antisocialistas pero no deja de ser cruel su afirmación de que "probablemente algunos de los fusilados merecieron su destino"20.

En nuestros días, la persecución ha sido valorada en algunas historias generales de la guerra o monografías acerca de la represión con criterios distorsionados que, lejos de situar el hecho en sus correctos límites, perpetúan los argumentos propagandísticos empleados por los perseguidores o los prejuicios de determinadas corrientes ideol6gicas acerca del hecho religioso ${ }^{21}$.

16 La obra de CARCel ORT, V:: La persecución religiosa en España durante la Segunda Republica; Rialp, Madrid, 1990, se centra más en los aspectos legislativos y políticos que en el análisis de las otras manifestaciones de la persecución para las que acepta las cifras ya propuestas. 1995.

17 Cfr. RiverA, J.: La persecución religiosa en la Dibcesis de Toledo (J936-1939): Toledo,

18 ThOMAS, H.: The Spanish Civil War, "Eyre and Spottiswood", London, 1961.

19 JACKSON, G.: La República espahola y la guerra civil. 1931-1939, Ed. Americana, México, 1967. De las varias ediciones en Espanta, cabe citar Orbis, Barcelona, 1985

20 H. ThOMAS: La guerra civil española; Grijalbo, Barcelona, 1983; p. 301.

21 Podemos citar un caso - por elegir alguno- en el que, al aludir a los eclesiásticos asesinados se sef̂ala su consideración como "activos agentes al servicio de los intereses de los sectores sociales rurales tradicionalmente dominantes"; cfr. COBO ROMERO, F.: La guerra civil y la represión franquista en la provincia de Jaén. 1936-1950, Diputación Provincial, Jaén, 1993; p. 261. También son lamentables los análisis sobre este tema de MORENO GÓMEZ, F.: La guerra civil en Córdoba; Madrid, 1985 y CASANOVA, J.: Anarquismo y revolución en la sociedad rural aragonesa. 1936-1938; Siglo XXI, Madrid, 1985.

La Jglesia en la Encrucijada Hispania Sacra 49 (1997) 
En cualquier caso, no cabe ninguna generalización en este sentido pues también es posible encontrar análisis rigurosos, que tienden a buscar una explicación coherente del fenómeno ${ }^{22}$.

\section{Cuestiones pendientes}

Llegado a este punto, podemos plantearlos cuáles son los retos historiográficos y las cuestiones pendientes a la hora de abordar el tema que nos ocupa. Como veremos, habrá que referirse fundamentalmente al empleo de nuevas fuentes y al paso de lo biográfico a lo cuantitativo, y de lo cuantitativo a lo cualitativo, buscando así el conocimiento - -lo más completo posible-- de las dimensiones que alcanzó y el significado que tuvo la persecución religiosa en España.

\section{Las fuentes}

Además de las habitualmente usadas (fundamentalmente la bibliografia y los Archivos Diocesanos, estos - lo decimos por experiencia propia en el caso de la diócesis de Badajoz- de dificil acceso para los investigadores) proponemos complementar la investigación en las siguientes direcciones:

\section{Registro Civil}

Fue sin duda R. Salas Larrazábal ${ }^{23}$ el primero en poner de relieve la importancia del Registro Civil como principal fuente para el conocimiento de las dimensiones cuantitativas de las muertes ocasionadas por la guerra civil.

22 "La violencia fue radical y sistemática contra lodo lo religioso. No tuvieron más suerte en la zona llamada republicana los sacerdotes o frailes con preocupación social y eficacia caritativa que los eclesiásticos menos sensibles a esos aspeclos. La represión no hizo distinciones. Buscó y asesinó al religioso por el hecho de ser religioso. Sacerdotes $\longrightarrow$ y para expresarnos con terminología popular-. amigos de los pobres cayeron de igual modo que los amigos de los ricos. La guerra exasperó el laicismo radical de la República. Seguramente, la lglesia pudo haber mejorado en España la labor de apostolado y la ayuda material a los más necesitados. Su acción social pudo tener poco éxito, al menos en términos cuantificables humanamente. Pero también es verdad que la acción social de que suele hablarse era la de las organizaciones y que no faltaron ejemplos de índividuos del clero regular y secular que dieron pruebas de dedicacion exclusiva hacia las clases sociales menos afortunadas, asi durante la Monarquía como durante la República. Y laicos también. El Régimen de 1931 excluyó con leyes sectarias la participación de los católicos en la vida pública. Ser creyente era motivo de desprestigio y desprecio..." Llera, L.: Historia de Espafia. 13(2) Espafia actual. El régimen de Franco; Gredos, Madrid, 1995; p. 124. En un sentido semejante puede verse ANDRÉS GALLEGO, J. (dir.) et all.: Historia de Espana. 13(1) España actual. La guerra civil; Gredos, Madrid, 1989; pp. 39-46 y 8995 
Para el estudio de la represión republicana, el Registro no plantea, en principio, problemas. Salvo en algunas ciudades, las muertes violentas ocasionadas por los partidarios de la República no se inscribieron en el momento de producirse pero, a medida que los nacionales ocupaban los pueblos, se procedió a este trámite. Los datos obtenidos a partir del Registro Civil se pueden estimar prácticamente como definitivos dado el interés en dejar constancia desde el primer momento de una muerte considerada gloriosa y tipificada con nitidez. Más aún, en el caso de los eclesiásticos, al tratarse de personas suficienternente conocidas, es presumible que la práctica totalidad de ellos hayan sido inscritos. El empleo de las partidas de defunción -aunque sean dificilmente agrupables por su dispersión geográfica - pueden ser útiles a la hora de precisar datos biográficos (edad, lugar y fecha de nacimiento, fecha de muerte...) que, al proceder de un testimonio oficial gozan de gran credibilidad.

\section{Archivo Histórico Nacional: Sección Guerra Civil. La "Causa General".}

La denominada "Causa General" fue instruida mediante un decreto del 26 de abril de 1940 con la finalidad de averiguar "los hechos delictivos cometidos en todo el territorio nacional durante la dominación roja" ${ }^{24}$. Dicho organismo, que tenía una misión exclusivamente informativa y que ejerció sus funciones en aquella parte del territorio español que estuvo sometida al dominio de la República, publicó en 1943 un libro editado por el Ministerio de Justicia, al que ya hemos aludido, en el que se recogía parte del resultado de la citada investigación, pero en el Archivo Histórico Nacional (Madrid) se encuentra una abundante y variada documentación formada en cada provincia por un informe-resumen y una serie de "piezas". Por lo que a nuestro tema de atención se refiere, son de especial interés las siguientes:

\section{"Pieza principal".}

Está constituida por una serie de documentos de contenido variado alusivos a las personas muertas, informes de autoridades y denuncias. Cada Ayuntamiento enviaba tres estadillos en los que se incluyen:

10 Relación de personas residentes en este término municipal que durante la dominación roja fueron muertos violentamente, desaparecieron o se cree fueran asesinados.

$2^{\circ}$ Relación de cadáveres recogidos en este término municipal de personas no conocidas como residentes en él que sufrieron muerte violenta durante la dominación roja.

23 A partir de su obra Pérdidas de la guerra; Planeta, Barcelona, 1977.

24 Citado por Rodrigugz MAGAllanes, R.: Cataluña durante la guerra civil. Documentos procedentes del Archivo de la Causa General,(Catálogo inédito) Madrid, octubre de 1990, p.2 
$3^{\circ}$ Relación de tormentos, torturas, incendios de edificios, saqueos, destrucciones de iglesias y objetos de culto, profanaciones y otros hechos delictivos que por sus citcunstancias, por la alarma o el terror que produjeron, deban considerarse como graves, con exclusión de los asesinatos que fueron cometidos en este têrmino municipal durante la dominación roja"2s.

\section{Pieza $3^{2}$ : Cárceles y sacas.}

Nos permite obtener datos sobre las cárceles y las personas detenidas, el trato que recibieron y los presos que fueron ejecutados sin mediar sentencia de un tribunal ("sacas").

\section{Pieza 10ª Persecución religiosa.}

Contiene informes de diversas instituciones civiles y eclesiásticas acerca de los sacerdotes y religiosos asesinados y de los templos o conventos destruidos y profanados.

Pieza $11^{\text {s: }}$ : Tesoro artístico y cultura roja. tico.

Incluye referencias acerca de los daños sufridos por el patrimonio artís-

Esta simple enumeración da una idea de que la "Causa General" constituye un impresionante acervo documental imprescindible para el estudio de la guerra civil y muy especialmente de la represión, pero a la vez tiene algunas limitaciones. Si un espíritu crítico y una elemental depuración de las fuentes puede hacernos "leer entre líneas" superando la evidente parcialidad, el principal problema que encontramos se deriva de su propia naturaleza, ya que se trata de informes de Ayuntamientos, Parroquias, Obispado, testimonios personales, etc. Es decir, que el contenido depende del interés o conocimientos del encargado de su redacción y, por tanto, es posible encontrar detallados relatos de testigos presenciales $o$, por el contrario, respuestas formularias y generalidades.

En la sección del fondo de este mismo Archivo Histórica Nacional relacionado con la guerra civil que se encuentra en el denominado "Archivo de Salamanca"26, también es posible localizar documentación que cuenta con la ven-

25 Archivo Histórico Nacional (en adelante A.H.N.); "Causa General", Pieza principal.

26 Por orden de la Secretaría General del Jefe del estado (29-mayo-37) se cré la "Delegación de Asuntos Especiales" con la misión de recoger la documentación relacionada con la masonería y un año más tarde (26-abril-38) aparecía en el Ministerio del Interior una delegación del Estado para "recuperar, clasificar y custodiar" la documentación procedente de entidades y personas pertenecientes al bando republicano "capaces de suministrar al Estado información referente a la actuación 
taja de proceder directamente de la zona republicana aunque tiene difícil acceso por poseer una catalogación muy sumaria.

\section{Prensa}

«No cabe la menor duda del alto valor testimonial que tiene para la Historia la prensa periódica editada durante la guerra civil. Con todas sus inexactitudes, con todas sus deliberadas falsedades informativas, constituye en su conjunto un singular documento ${ }^{27}$. ,

Por este motivo conviene consultar series completas y números sueltos de la prensa publicada por ambos bandos. Lo más interesante de esta fuente no son tanto los datos que proporciona -en general inexactos- como la información acerca del ambiente que transmite.

"Lugares de memoria"

Por "lugares de memoria" -en terminología de P. Nora-- entendemos los soportes externos, las marcas tangibles de la memoria histórica que reelaboran la percepción y fijan el recuerdo de los hechos ocurridos ${ }^{28}$.

En el caso de la persecución religiosa, el recuerdo se aviva fundamentalmente en cada pueblo mediante las cruces y lápidas en honor de los Caídos que figuran, en ocasiones, en los templos parroquiales y en las Catedrales así como en los monumentos erigidos en las sepulturas de las víctimas o en los lugares en que se produjeron las muertes. En ambos casos, suelen ser de utilidad como complemento a la documentación empleada.

Circunstancialmente, será posible el recurso a otras fuentes de carácter más localizado: testimonios orales ${ }^{29}$ (útiles, aunque con la prudencia necesaria,

de sus enemigos'26. Una vez suprimidos estos organismos los fondos fueron confiados al Archivo Histórico Nacional y se conservan en Salamanca. Se distribuyen en varias secciones: "Especial", "Político-sindical" (comprende una serie de carpetas con documentación muy variada incautada en los centros políticos y militares de la zona republicana) y "Bibliográfica".

27 PALACIO ATARD, V. en GONZÁlez GARCiA, P. (coord.): La guerra civil espaniola. Exposición itinerante; Ministerio de Cultura, Madrid, 1980; p. 54

28 NORA, P. Les lieux de memoire, PUF, París, 1985, cit. por. CALvo, M. et all. "Los lugares de memoria de la guerra civil en un centro de poder, Salamanca, 1936-1939" en AROSTEGUI, J. (Coord.): Historia y Memoria (I) op. cit.; p.297.

29 Como ejemplo del uso de los testimonios personales puede verse: "La persecució religiosa de 1936 a Catalunya. Testimoniatges a cura de Joseph Massot i Muntaner"; Abadía de Montserrat, 1987. Es de máxima urgencia recuperar los recuerdos y memorias que dan fe de la época de persecución y del recuerdo de los mártires.

La Iglesia en ta Encrucijada

Hispania Sacra 49 (1997) 
especialmente para los núcleos rurales), "Libros de enterramiento" conservados en los cementerios, Registros de entrada y salida de Prisiones, Listados del "Santuario Nacional de la Gran Promesa", etc.

\section{El estudio de las diversas manifestaciones}

La persecución religiosa es un fenómeno complejo que, por tanto, no cabe reducir a los asesinatos de eclesiásticos. Por lo tanto, un estudio completo deberá tener en cuenta, al menos, las siguientes dimensiones:

Asesinatos de obispos, sacerdotes, religiosos, monjas y seminaristas.

Asesinatos de seglares por motivos religiosos.

«No es posible dar ni siquiera cifras aproximadas del número de seglares asesinados por su militancia en movimientos y asociaciones de la Iglesia, porque no existen estadísticas fiables, pero fueron probablemente varios millares, habida cuenta de los datos ofrecidos en algunos martirologios diocesanos ${ }^{30} . "$

En general, resulta muy difícil separar la persecución religiosa de la represión de carácter sociopolítico. Buena prueba de ello son los hombres y mujeres, en ocasiones vinculados a organizaciones como la Juventud de Acción Católica, que murieron por motivaciones en las que se entrecruzaban todos esos factores. Un informe de la Diócesis de Badajoz así lo reconocía al afirmar que más del $30 \%$ de los asesinados lo fue por ser católicos practicantes aunque la cifra no es excluyente "porque los marxistas identificaban lo religioso en todos los otros aspectos" ${ }^{11}$ :

"Aunque hay poca constancia de los actos heroicos realizados por estos mártires, hay la suficiente para saber que en la mayoría de los casos, practicaron en la prisión actos de piedad, rezando el rosario y otras oraciones y, cuando contaban entre ellos con algún sacerdote, recibieron el sacramento de la penitencia. Al mismo tiempo consta que muchos de ellos, alentados por los sacerdotes, compañeros de martirio, ofrendaron a Dios su vida y convirtieron fácilmente el motivo político de su detención en verdadero martirio por la $\mathrm{Fe}^{32}$."

30 CARCEL, ORTJ, V.: La persecución religiosa ...; op. cit.; p. 301

3 MONTERO MORENO, A.: op. cit. p.542.

32 Cit. por MONTERO MORENO, A.: op. cit. p. 543. 
Las víctimas cayeron en muchas ocasiones dando gritos de "iViva Cristo Rey!" y "iArriba España!" pero la expresión de las mejores virtudes religiosas no se agotó solo en la aceptación de la muerte, otras veces las propias circunstancias en que se desarrollaron los hechos, permitieron a algunos dar la vida por salvar a un compañero o por no separarse de sus familiares.

Detenciones y encarcelamientos de eclesiásticos y seglares. Organización clandestina de la caridad y el culto.

Paralelamente a los asesinatos, se produjo frecuentemente la detención y el ingreso en prisión de sacerdotes y religiosos que aprovecharon esa circunstancia para ejercer su ministerio confortando espiritualmente a sus compañeros.

Las grandes matanzas de 1936 vaciaron las cárceles pero no significaron el final de las detenciones que se siguieron sucediendo durante 1937 y 1938. En estas circunstanciás no decayó, al contrario, la práctica religiosa. Los sacerdotes que permanecían escondidos o disfrazados absolvían a los penitentes, animaban y confortaban a los presos. En las prisiones pudieron organizarse, en otras ocasiones, incluso celebraciones religiosas clandestinas ${ }^{33}$.

En la zona donde el dominio republicano se consolidó no se pudo celebrar la Santa Misa en dos años, pero sí el Bautismo y la Penitencia. Algunas veces era una comadrona católica la que administraba ocultamente el bautismo a los recién nacidos, otras veces, las mismas madres acudían con sus hijos, valiéndose de diversos pretextos, a que personas cristianas los bautizaran. Otros católicos se encargaron de consumir las Sagradas Formas para evitar la profanación y salvaron vasos, omamentos sagrados y fragmentos de imágenes que pudieron ser reintegrados al normalizarse la situación. La proscripción de toda referencia religiosa no impidió que los católicos buscaran otros medios de expresión de sus creencias: en ocasiones varias familias se reunían en "templos" improvisados para orar y consolarse mutuamente; otras veces, se adoptaron signos y palabras convencionales de saludo pues la persecución llegó hasta a considerar sospechosos el empleo de fórmulas tradicionales.

Incendios, saqueos y profanaciones.

Los edificios destinados al culto (iglesias, ermitas y conventos) fueron por regla general convertidos en cárceles, casas del pueblo, almacenes, garajes,

33 "Tentamos una cruz en un allarcito portatil. formado con unas cajas de hilos; hactan de floreros latas de leche condensada.. Todas estas cosas, terminados los rezos y cánticos, se ocultaban a diario en uno de los petates de las dos hermanitas de los ancianos desamparados de Don Benito, que estaban detenidas con nosotras"; SPINOLA DE GIRONZA, A.: op. cit.; p. 112.

La Iglesia en la Encrucijada

Hispania Sacra 49 (1997) 
cuadras, etc. y sufrieron daños de diversa consideración aunque en su mayoría reparables. Pero el contenido de esos templos fue saqueado y quemado entre escenas sacrílegas, burlas, profanaciones, parodias de las ceremonias religiosas y realización de hechos incalificables con las imágenes. El Santísimo Sacramento, que en muchas ocasiones había podido ser consumido con reverencia, se convirtió en otras en objetjvo preferente.

*Si alguna iglesia quedó intacta, después de quemar las imágenes, retablos, altares y enseres de culto, fue por la esperanza de poder utilizarla como garaje o almacén público. Se calcula que en Cataluña fueron destruidos unos 7.000 edificios religiosos, si bien algunas iglesias y edificios de mayor antigüedad fueron salvados gracias a la intervención de autoridades locales, que las cerraron totalmente al público y de la mayor parte de ellas quitaron las imágenes, las campanas y otros objetos. Los muros de muchas iglesias incendiadas fueron derribados para evitar el bochornoso espectáculos de los restos de aquellos espléndidos edificios y lugares de culto. Otros fueron reparados para los fines antedichos, después de haber borrado de ellos cualquier emblema o símbolo religioso" 34 .»

La relación de pérdidas de obras religiosas de gran valor artístico, y en la mayoría de las ocasiones ni siquiera catalogadas, sería muy elevada y apenas resultaría significativo citar algunos de los casos más notorios ${ }^{35}$.

\section{El problema de las cifras}

Los datos que suelen ofrecerse sobre víctimas eclesiásticas de la persecución religiosa, desde el 18 de julio de 1936 hasta el final de la guerra (a ellos habría que añadir los sacerdotes, religiosos y seminaristas muertos en la Revolución de Octubre de 1934) son los que presentó en su día A. Montero: seis mil ochocientos treinta y dos, de los cuales cuatro mil ciento ochenta y cuatro pertenecen al clero secular, incluidos doce obispos, un administrador apostólico y los seminaristas; dos mil trescientos sesenta y cinco son religiosos y doscientas ochenta y tres religiosas. Los estudios monograficos que se han llevado a cabo con posterioridad sobre algunas diócesis inclinan a creer que la cifra final se aproxima a las siete mil víctimas. En cualquier caso, sesenta años después de la persecución, no podemos señalar aún con precisión cuántos sacerdotes y religiosos perecieron a consecuencia de ella.

34 CARCEl ORTI, V.: La persecución religiosa ...; op. cit p. 207.

35 Cfr. como ejemplos: MINISTERIO DE JUSTICIA: La dominación roja en España; Madrid, 1943; pp. 193-200; CoVARSI, A.: "Destrucción del tesoro artistico nacional en la provincia de Badajoz" en Revista del Centro de Estudios Extremeños, (1937/1939); RIVERA RECiO, Juan F.: La persecución religiosa en la Diócesis de Toledo (1936-1939); Toledo, 1995; pp. 81-118.

La Iglesia en la Encrucijada Hispania Sacra 49 (1997) 
Carecemos también de un estudio preciso sobre el reparto geográfico de los asesinatos por la dificultad en hacer coincidir los límites provinciales con los diocesanos y porque a los datos del clero secular habría que añadir los de las comunidades de religiosos pero al menos a partir de los primeros se puede comprobar que, si bien la persecución fue más intensa, lógicamente, en aquellas zonas donde la represión en general fue más dura, puede decirse que abarca la práctica totalidad del territorio en que se extendió la represión republicana. Los mayores porcentajes se alcanzan en Cataluña y en la franja central mientras que el norte resultó menos castigado.

Más difícil aún es precisar qué porcentaje suponen las muertes de eclesiásticos sobre el total de víctimas de la represión republicana. Podemos intentar una aproximación suponiendo que los religiosos se reparten en una proporción similar a la de los sacerdotes seculares y haciendo una comparación con las cifras globales que hemos obtenido a partir de los datos del Instituto Nacional de Estadística:

\begin{tabular}{lccccc}
\hline Zona & Sacerdotes & $\begin{array}{c}\text { Religiosos } \\
\text { (estimados) }\end{array}$ & Total & Represion & $\begin{array}{c}\text { Porcentaje } \\
\text { eclesiasticos }\end{array}$ \\
\hline Andalucía- & 539 & 308 & 847 & 10721 & 7.90 \\
Extremadura & 285 & 163 & 448 & 2916 & 15.35 \\
Aragón & 1536 & 877 & 2413 & 8826 & 27.34 \\
Cataluña & 953 & 544 & 1497 & 23369 & 6.41 \\
Franja central & 578 & 330 & 908 & 7811 & 11.62 \\
Levante & 252 & 144 & 396 & 2933 & 13.50 \\
Norte & & & 324 & & \\
$?$ & $\mathbf{4 1 4 3}$ & $\mathbf{2 3 6 5}$ & $\mathbf{6 8 3 2}$ & $\mathbf{5 6 5 7 6}$ & $\mathbf{1 2 . 0 8}$ \\
\hline Total & & & & & \\
\hline
\end{tabular}

Fuente: MONTERO MORENO, A.: op. cit.; pp. 763-767.

Elaboración propia

Sin olvidar que la estimación de los religiosos habrá introducido probablemente alguna distorsión, este cuadro parece suficientemente expresivo: en Cataluña y la región levantina es donde las víctimas eclesiásticas alcanzan un porcentaje más elevado sobre el total de bajas ocasionadas por la represión, el norte se sitúa en una posición intermedia mientras que en el sur y en la franja central los valores son aún más bajos. En todo caso el promedio nacional es significativo (12\%) y demuestra que sin duda fueron los eclesiásticos el sector

La lglesia en la Encrucijada

Hispania Sacra 49 (1997) 
proporcionalmente más castigado por la represión republicana que queda asi necesariamente caracterizada por sus motivaciones antirreligiosas.

También resulta importante precisar el reparto cronológico de estas muertes: para el total del territorio nacional únicamente disponemos de los datos que aparecen en la tabla siguiente y mediante los cuales se puede comprobar que la mayoría de ellas tuvieron lugar en los primeros meses de la guerra, y especialmente en agosto y septiembre, pero todavía en 1937, 38 y 39 continuaron los fusilamientos de religiosos y sacerdotes.

\begin{tabular}{ccc}
\hline FECHA & ViCTIMAS & PORCENTAEE \\
\hline Anteriores al 18-julio-1936 & 29 & 0.42 \\
VII-36 & 877 & 12.84 \\
VIII-36 & 2012 & 29.45 \\
IX-36 & 1008 & 14.75 \\
X-36 & 536 & 7.85 \\
XI-36 & 524 & 7.67 \\
XII-36 & 236 & 3.45 \\
1937 & 172 & 2.52 \\
1938 & 43 & 0.63 \\
1939 & 12 & 0.18 \\
$?$ & 1383 & 20.24 \\
\hline TOTAL & 6832 & \\
\hline
\end{tabular}

Fuente: Cálculo por J. SALAS LARRAZábal a partir de los datos del libro de A. Montero; en La guerra de España desde el aire; Ariel, Barcelona, 1972; pp. 489-491

Cuando se intenta dar respuesta a todas estas cuestiones, es fácil constatar la necesidad de una revisión del catálogo de víctimas de la persecución religiosa, labor que estamos llevando a cabo a partir de la obra de Montero convenientemente complementada con las monografias diocesanas y regionales publicadas con posterioridad a 1961. A partir de una base de datos elaborada con toda esa información, la aplicación de métodos estadísticos nos permitirá un balance definitivo y la obtención de sugerentes conclusiones.

\section{De lo cuantitativo a lo cualitativo.}

Sentada esta premisa, la reconstrucción lo más completa posible del catálogo de víctimas, será posible dar un paso más que consiste en superar lo puramente cuantitativo (análisis numérico y estadístico) para llegar a lo cualitativo, 
obteniendo así un perfil de las características de la persecución religiosa en España.

II LA PERSECUCIÓN RELIGIOSA EN LA COMARCA EXTREMEÑa DE "LOS MONTES": UNA PROPUESTA METODOLÓGICA.

En esta segunda parte, aplicamos los criterios propuestos al caso concreto de una comarca extremeña para que sirva como pauta de lo que puede hacerse en las diversas provincias como paso previo para una síntesis nacional que presentaremos próximamente.

La delimitación del campo de estudio: la comarca bajoextremeña de "Los Montes del Guadiana"

Un trabajo acerca de la persecución religiosa debe escoger en primer lugar cuál ha de ser su campo de estudio. Tradicionalmente se han elegido criterios personales o territoriales. Entre los primeros cabe citar los martirologios de congregaciones religiosas que recogen todas sus víctimas con independencia de los lugares en que se produjeran las muertes y, por lo tanto, sin posibilidad de establecer ninguna valoración de tipo cuantitativo o cualitativo. En el caso de los criterios territoriales han prevalecido los trabajos centrados en el ámbito diocesano. Sin embargo, para un estudio con las características del que proponemos parece que el marco más adecuado es el de las provincias subdivididas en comarcas pues permite incluir todas las muertes ocurridas en un territorio (con independencia de que se trate de sacerdotes o de religiosos), es un primer paso hacia el análisis regional y la síntesis nacional y facilita el relacionar la persecución religiosa con otras dimensiones como la represión de carácter sociopolítico o la evolución militar del conflicto. Por otra parte, dada la complejidad del mapa eclesiástico español (sometido además a variaciones entre 1936 y la actualidad) seguir la fronteras de diocesis y arciprestazgos nos obligaría a separar pueblos de la misma comarca y que atravesaron circunstancias semejantes durante la guerra.

En el caso concreto que nos ocupa, estamos ante una zona situada en el noreste de la provincia de Badajoz, junto a los límites de Badajoz con Ciudad Real, Cáceres y Toledo, y que, dada su extensión, su escaso poblamiento y su aislamiento de las principales vías de comunicación, recibió en ocasiones el nombre de "la Siberia extremeña". En concreto, vamos a centrar nuestra atención sobre una serie de localidades pertenecientes a la Archidiócesis de Toledo y que en 1936 estaban integrados en los Partidos Judiciales de Puebla de Alco-

La Iglesia en la Encrucijada

Hispania Sacra 49 (1997) 
cer y Herrera del Duque: Baterno, Capilla, Casas de Don Pedro, Castilbianco, Fuenlabrada de los Montes, Garbayuela, Garlitos, Helechosa y Bohonal, Hernera del Duque, Peloche, Peñalsordo, Puebla de Alcocer, Risco, Siruela, Talarrubias, Tamurejo, Valdecaballeros, Villarta de los Montes y Zarza Capilla.

El único episodio de cierta relevancia ocurrido en los primeros momentos de la guerra tuvo lugar en Talarrubias donde se concentró en rebeldía toda la línea de la Guardia Civil y la de Herrera del Duque hasta que el 24 de julio se presentó un oficial del cuerpo, de la provincia de Ciudad Real, y consiguió que ellos y sus familiares marcharan con él. Como consecuencia, la zona quedaría durante toda la guerra en la retaguardia republicana y las manifestaciones tempranas de brutalidad acabaron por dejar paso a un fenómeno contrario de apatía y alejamiento del conflicto. La ocupación de estos pueblos por los nacionales tuvo lugar en marzo de 1939 sin producirse combates.

En este marco espacial, se sitúa este trabajo en el que, como hemos apuntado, vamos a proceder de acuerdo con una metodología y una sistematización de los datos disponibles ${ }^{36}$ que puede ser aplicada igualmente a otros territorios.

Una primera distinción debe hacerse entre la persecución sobre las personas y la que afectó a las cosas.

La persecución sobre las personas

Cabe señalar las siguientes situaciones:

Asesinatos de eclesiásticos.

Detenciones, encarcelamientos y otras circunstancias.

Persecución religiosa y represión. Los seglares.

36 Éstos proceden, fundamentalmente, de RiVERA, J.: op. cit. y Archivo Histórico Nacional. Sección Guerra Civil. "Causa General" Legs. 1052-1056. 


\section{Asesinatos de eclesiásticos}

Podemos proceder según los siguientes pasos:

Establecer la nómina de sacerdotes y comunidades religiosas con residencia en la zona.

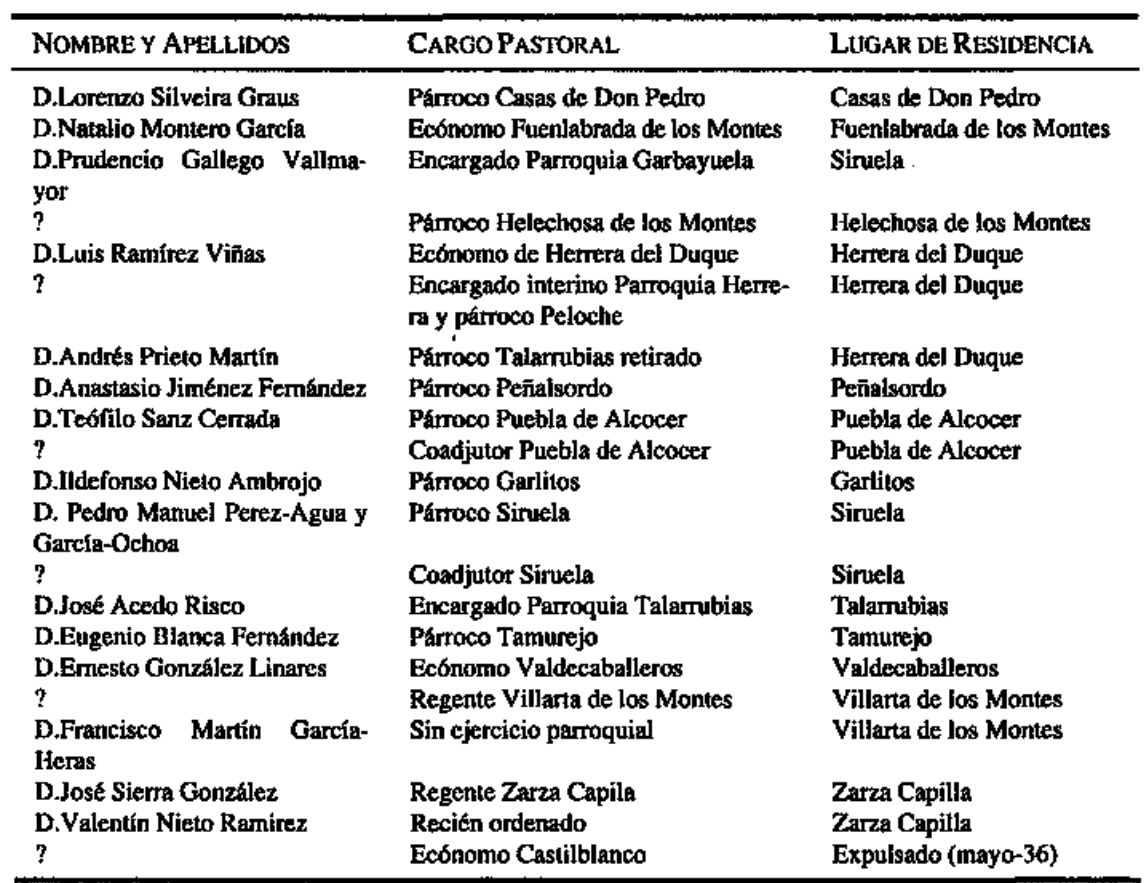

A ellos hay que añadir dos sacerdotes llegados accidentalmente: D. Benito González Pozuelo, párroco en Jerez de los Caballeros (provincia y diócesis de Badajoz) y D.Ildefonso Torrejón Peña, párroco de Mengabril (provincia de Badajoz y diócesis de Plasencia).

Existían tres comunidades religiosas:

\begin{tabular}{lcc}
\hline COMUNiDAD RELIGIOSA & LOCALIDAD & N $^{\circ}$ MIEMBROS \\
\hline Franciscanas de la Tercera Orden Regular & Siruela & 13 \\
Religiosas Concepcionistas Franciscanas & Puebla de Alcocer & 4 \\
Hijas de Cristo Rey & Talarnubias & $?$ \\
\hline
\end{tabular}

La Iglesia en la Encrucijada

Hispania Sacra 49 (1997) 
A partir de ahora prescindimos de los casos de sacerdotes que se encontraban en sus pueblos natales y resultaron muertos fuera de la comarca ${ }^{37}$. En general parece conveniente adoptar este criterio pues se evita el peligro de repeticiones a la hora de extrapolar los datos a nivel regional o nacional.

Precisar quiénes fueron los eclesiásticos asesinados en la comarca:

\begin{tabular}{lclcc}
\hline NOMBRE & EDAD & \multicolumn{1}{c}{ LuGAR DE MUERTE } & FECHA \\
\hline D.José Acedo Risco & 32 & "Cementerio Viejo" Talarrubias & $28 / 08 / 36$ \\
D.Eugenio Blanca Fernández & 38 & Tamurejo & $7 / 09 / 36$ \\
D.Prudencio Gallego Vallmayor & 30 & Siruela & $18 / 08 / 36$ \\
D.Benito González Pozuelo & 59 & Puebla de Alcocer & $7 / 08 / 37$ \\
$\begin{array}{l}\text { D.Francisco Martín García- } \\
\text { Heras }\end{array}$ & 42 & Villarta de los Montes & $18 / 10 / 36$ \\
D.Natalio Montero García & 60 & "Portezuelo" (Tmno. Fuenlabrada) & $2 / 09 / 36$ \\
D.Ildefonso Nieto Ambrojo & 41 & Siruela & $18 / 08 / 36$ \\
D.Teofilo Sanz Cerrada & 57 & "Puente del Zújar" (Tmno. Puebla & $18 / 08 / 36$ \\
& & de Alcocer) & \\
D.José Sierra González & 44 & "Cementerio" Herrera del Duque & $25 / 10 / 36$ \\
D.Lorenzo Silveira Graus & 61 & "Las Caleras"(Tmno.Talarrubias) & $6 / 09 / 36$ \\
D.lldefonso Torrejón Peña & 37 & Casas de Don Pedro & $26 / 08 / 36$ \\
\hline
\end{tabular}

Estudio parcial de algunos aspectos

Exponemos a continuación algunas cuestiones particulares de cierto interés que en las síntesis territoriales más amplias deberían complementarse con gráficos.

\section{Muertes sobre el total de clero residente en la comarca}

De un total de 21 sacerdotes residentes en la comarca fueron asesinados 11 (dos de ellos fuera), es decir un $52,3 \%$. Añadiendo los dos extradiocesanos y eliminando los que murieron en la provincia de Toledo la cifra se mantiene igual.

37 D.Luis Ramirez Vifras, asesinado el 15-agosto-1936 en Mora (Toledo) y D.Pedro Pérez-Agua y Garcia-Ochoa, el 9-septiembre-1936 en Sonseca (Toledo). 


\section{Fechas}

¿Fue la persecución religiosa un fenómeno limitado en el tiempo o puede decirse que perduró a lo largo de toda la guerra? La distribución cronológica de las víctimas puede ayudar a precisar esta cuestión pero no cabe olvidar que es algo que debe ser contrastado con las informaciones que poseemos acerca de la proscripción del culto en la zona hasta marzo de 1939. En cualquier caso, las muertes violentas suelen concentrarse en los primeros meses de la guerra. (especialmente en agosto y septiembre) y la comarca de Los Montes no es una excepción mientras que lo ocurrido en 1937 no deja de ser un caso aislado.

\begin{tabular}{ccc}
\hline PECHA & NoVICTIMAS $^{\circ}$ & PORCENTAJE \\
\hline ago-36 & 5 & 45.45 \\
sep-36 & 3 & 27.27 \\
oct-36 & 2 & 18.18 \\
1937 & 1 & 9.09 \\
\hline
\end{tabular}

\section{Lugares de referencia}

A la hora de elaborar un mapa provincial en el que se reflejen las pérdidas eclesiásticas, puede resultar difícil precisar la localidad a que deben adscribirse las víctimas pues, en ocasiones, no coinciden el lugar de residencia habitual con el de muerte, y a veces los vecinos de un mismo pueblo eran asesinados en otros términos municipales de las proximidades:

«La represión, y cualquier ruptura de la normalidad, como implica un cambio de actitud cotidiana y requiere cierto ejercicio de impudicia, es más fácil hacerla fuera del ámbito cotidiano propio ${ }^{38} . "$

Por eso, puede resultar de interés un nuevo concepto: el de "lugar de referencia", entendiendo como tal el pueblo en el que se encontraba el asesinado en el momento de ser sacado para la ejecución. Como vemos en el caso de los eclesiásticos que nos ocupan, no siempre coinciden los tres puntos: lugar de residencia, lugar de muerte y "lugar de referencia".

36 ANDRES GALlEGO, J.: op. cit.; p.33.

La Iglesia en la Encrucijada

Hispania Sacra 49 (1997) 


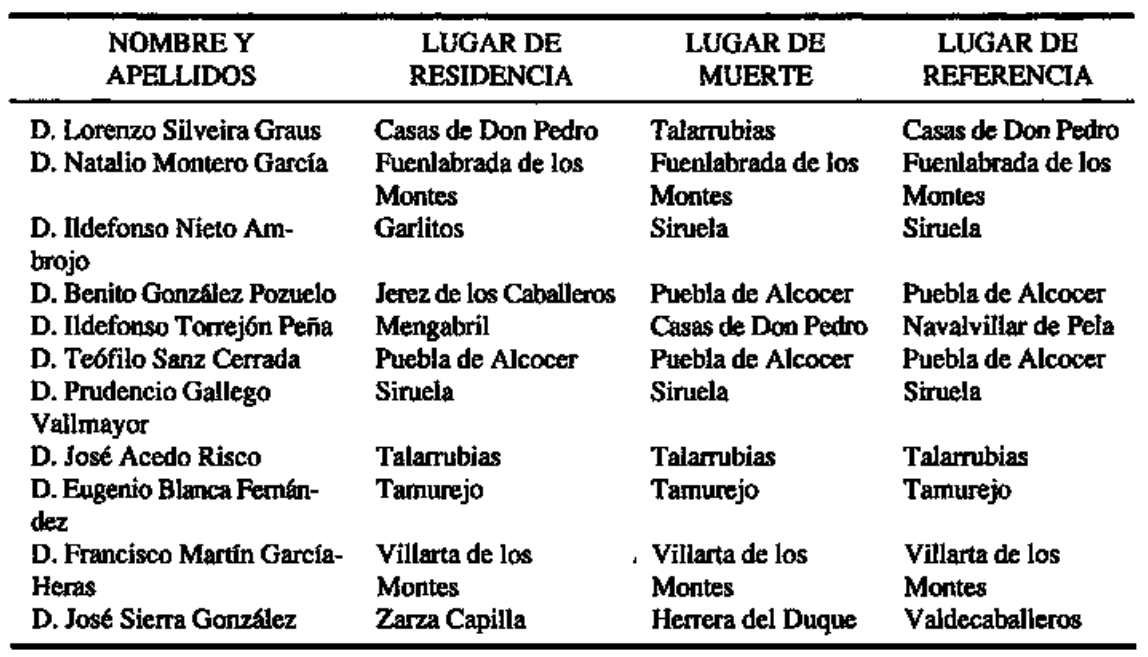

\section{Forma de producirse la muerte}

Las circunstancias en que se produjeron las muertes a consecuencia de la represión republicana, cabe sistematizarlas de acuerdo con los siguientes criterios, fundamentalmente cuantitativos pero que ponen el acento sobre una dimensión cualitativa esencial: evidentemente, no responden a los mismos planteamientos y responsabilidades los llamados "paseos" o ejecuciones arbitrarias e individuales que una matanza colectiva en la que el número de víctimas es mucho mayor.

Muertes aisladas: en aquellas ocasiones en que la muerte fue muy selectiva y afect6 a personas concretas, normalmente de algún protagonismo religioso, social o político.

Grupos formados sólo por eclesiásticos.

Grupos formados por eclesiásticos y seglares:

3.a) Matanzas indiscriminadas: especialmente en momentos de especial tensión como podian ser los previos a la llega de las tropas nacionales.

3.b) Grupos reducidos (entre 5 y 15 personas): en los que predominaban generalmente las denominadas "fuerzas vivas" de la localidad (propietarios, profesionales liberales, sacerdotes, etc.). 
3.c) Fusilamientos masivos (por encima de las 15 personas): en pueblos donde la represión alcanz 6 a grandes proporciones y afectó a todas las clases sociales.

En la comarca de Los Montes las muertes de eclesiásticos tuvieron lugar predominantemente $(\mathbf{7 2 , 7 3 \% )}$ en grupos reducidos formados por sacerdotes y seglares.

\section{Detenciones, encarcelamientos y otras circunstancias}

Normalmente, el aspecto más llamativo de la persecución es el de las muertes pero no es el exclusivo. Previo a ellas hay que referirse a las detenciones y encarcelamientos así como a las peripecias sufridas por los sacerdotes y comunidades religiosas que lograron sobrevivir.

En la comarca, ingresaron en prisión 13 sacerdotes mientras que fueron asesinados $2 \sin$ que conste el haber pasado antes por las cárceles republicanas. De los que estuvieron detenidos serían fusilados 9, en cambio, después de las más diversas penalidades, los 4 restantes lograron llegar a zona nacional o pasar desapercibidos hasta el final de la guerra. Por último hay un pequeño grupo formado por 5 sacerdotes que, generalmente debido a su avanzada edad, no fueron grandemente molestados.

De algunos de estos sacerdotes consta expresamente, cómo ejercieron su ministerio durante su estancia en prisión. Así, D.Lorenzo Silveira, párroco de Casas de don Pedro evitó con sus amonestaciones que un compañero de infortunio se suicidara; los que estuvieron en la cárcel con D.Natalio Montero, ecónomo de Fuenlabrada, atestiguan su vida de oración y sus indicaciones de que era "necesario preparar el alma, porque seguramente nos matarán". Lo mismo podría decirse de los sacerdotes de Siruela D.Ildefonso Nieto y D.Prudencio Gallego que confesaban y exhortaban a los encarcelados y de D.José Acedo Risco que, al advertir que se acercaba la hora del fusilamiento, confesó a los que con él se encontraba y les administró la Sagrada Comunión con un trozo de pan allí mismo consagrado. En otras ocasiones (como es el caso de D.José Sierra, regente de Zarza Capilla) absolvían a las restantes víctimas en el momento de la muerte. Don Andrés Prieto, sacerdote retirado y residente en Herrera del Duque administró dos veces el bautismo durante el período de control republicano.

Por lo que a las comunidades religiosas se refiere, las cuatro concepcionistas franciscanas de Puebla de Alcocer vivieron fuera del convento y en este tiempo falleció una de ellas. Las de Siruela fueron expulsadas el 24 de julio reuniéndose las trece religiosas en una casa particular. En 1939 componían la 
comunidad once ${ }^{39}$. En Cabeza del Buey se refugiaron las Hijas de Cristo Rey procedentes de Talarrubias donde habían pasado por toda clase de tribulaciones, cárcel incluida, y se ganaban la vida trabajando en menesteres agrícolas:

«Fueron conducidas las madres a la cárcel juntamente con otras religiosas y señoras de la localidad, esperando sería aquella su última noche de vida, se prepararon para el martirio, pues cada madrugada había fusilamientos. A la mañana siguientes, la superiora fue sometida a un largo interrogatorio; lo mismo hicieron con las demás religiosas, aunque por separado, para ver si se contradecian en sus declaraciones. Volvieron a llamar a la superiora, y esta vez más encolerizados, mandaron fuera llevada a un calabozo de los más tétricos, sin luz, sin tener donde descansar; allí esperó, como era de suponer, la hora de que volvieran a buscarla para fusilarla; pero Dios Nuestro Señor, en sus altos designios, no lo permitió, y después de algunos días de sufrimiento, fue puesta en libertad, gracias a los buenos oficios de uno de los guardias, a quien Dios habrá premiado su caridad. Las otras madres ya habian salido de la cárcel ${ }^{40} . "$

Persecución religiosa y represion. Los seglares.

Como hemos apuntado, resulta difícil separar la persecución religiosa de la represión de carácter sociopolítico. En cambio, sí parece posible poner en relación el número de bajas eclesiásticas con el total de muertes a consecuencia de la represión en cada pueblo y con el total de la zona:

\begin{tabular}{lccc}
\hline LOCALIDAD & N $^{\circ}$ VICTIMAS & $\begin{array}{c}\text { ViCTIMAS } \\
\text { ECLESIASTICAS }\end{array}$ & PORCENTAJE \\
\hline Batemo & 0 & 0 & \\
Capilla & 0 & 0 & 12.50 \\
Casas de Don Pedro & 8 & 2 & \\
Castilblanco & 16 & 0 & 12.50 \\
Fuenlabrada de los Montes & 8 & 1 & \\
Garbayuela & 0 & 0 & \\
Garlitos & 0 & 0 & \\
Helechosa de los Montes & 8 & 0 & \\
Herrera del Duque & 12 & 0 & \\
Peloche & 0 & 0 &
\end{tabular}

39 Rtvera, J.: op. Cit.; pp. 519-521.

40 Relación de las Religiosas Hijas de Cristo Rey, p. 3 cit. por MONTERo MORENO, A.: op. cit, p.494.

La Iglesia en la Encrucijada Hispania Sacra 49 (1997) 


\begin{tabular}{lrcc}
\hline LOCALIDAD & N $^{\circ}$ VICTIMAS & $\begin{array}{c}\text { VICTIMAS } \\
\text { ECLESIASTICAS }\end{array}$ & PORCENTAJE \\
\hline Peñalsordo & 3 & 0 & \\
Puebla de Alcocer & 30 & 1 & 6.67 \\
Risco & 0 & 0 & \\
Siruela & 29 & 3 & 10.34 \\
Talarrubias & 29 & 1 & 3.45 \\
Tamurejo & 1 & 1 & 100 \\
Valdecaballeros & 14 & 1 & 7.14 \\
Villarta de los Montes & 3 & 1 & 33.33 \\
Zarza Capilla & 2 & 0 & \\
\hline Total & 163 & 11 & 6.75 \\
\hline
\end{tabular}

El porcentaje comarcal se encuentra en proporción semejante al total provincial (6\%) y al que habíamos calculado para la zona sur (Andalucía y Extremadura): $7,9 \%$.

También cabe precisar aquí aquellos casos de seglares en que las motivaciones religiosas de su muerte estén más patentes así como aquellas circunstancias de la vida social que se vieron alteradas por la persecución religiosa (prohibición del culto, organización clandestina ...).

En la localidad de Fuenlabrada de los Montes consta el nombre de Obdulia Yegros Álvarez, víctima de su arraigada vida cristiana que por negarse a entregar una imagen sagrada, fue detenida y a los pocos días fusilada en las tapias del cementerio (12-septiembre-1936) y en Siruela, el joven Prudencio Moreno, temiendo que le arrebatasen el crucifijo en el momento de ser asesinado (18-agosto-1936) se lo trag6 y dijo a los verdugos: "Ahora, tirad"

La persecución sobre las cosas.

En el siguiente cuadro puede verse un primer balance de los daños sufridos por los edificios de culto y ajuar litúrgico que da una ligera idea de las importantes pérdidas sufridas por la comarca ${ }^{42}$. Quizás el caso más notable fuera el del magnifico retablo plateresco de Casas de Don Pedro cuyas pinturas sirvieron como suelo para un escenario en la "Casa del Pueblo".

41 RIVERA, J.: op. cit. pp. 315 y 326

42 Covarsi, A.: op. cit.

La Iglesia en la Encrucijada Hispania Sacra 49 (1997) 


\begin{tabular}{|c|c|c|c|}
\hline LOCALIDAD & EDIFICIOS RELIGIOSOS & PÉRDIDAS SUFRIDAS & USO POSTERIOR \\
\hline Baterno & $\begin{array}{l}\text { Parroquia } \\
\text { Ermita de Ntra.Sra. del } \\
\text { Fuego }\end{array}$ & $\begin{array}{l}\text { Interior totalmente destruido } \\
\text { Interior totalmente destruido }\end{array}$ & $\begin{array}{l}\text { Casa del Pueblo } \\
\text { Hospital y cuartel }\end{array}$ \\
\hline \multirow[t]{2}{*}{ Capilla } & Parroquia & Interior totalmente destruido & $\begin{array}{l}\text { Depósito de vive- } \\
\text { res }\end{array}$ \\
\hline & Ermita de San Sebastián & Totalmenie destruido & \\
\hline \multirow{2}{*}{$\begin{array}{l}\text { Casas de Don } \\
\text { Pedro }\end{array}$} & Parroquia & Interior totalmente destruido & \\
\hline & $\begin{array}{l}\text { Ermita de la Virgen de los } \\
\text { Remedios }\end{array}$ & Interior totalmente destruido & \\
\hline \multirow[t]{2}{*}{ Costifblance } & Parroquig & Interior totalmente destruido & $\begin{array}{l}\text { Almacen de gra- } \\
\text { nos y cocina }\end{array}$ \\
\hline & Emita de San Matías & Totalmente destruido & $\begin{array}{l}\text { Depósito de ma- } \\
\text { quinaria agrícola }\end{array}$ \\
\hline \multirow{3}{*}{$\begin{array}{l}\text { Fuenlabrada de } \\
\text { los Montes }\end{array}$} & Parroquia & Interior totalmente destruido & \\
\hline & Enmita del Calvario & Interior totalmente destruido & \\
\hline & Ermita de Santa Ana & Interior totalmente destruido & \\
\hline \multirow{2}{*}{$\begin{array}{l}\text { Garbayuela } \\
\text { Garititos }\end{array}$} & Parroquia & Parcialmente saqueado & Garaje \\
\hline & Parroquia & Interior totalmente destruido & $\begin{array}{l}\text { Garaje y Casa del } \\
\text { Pueblo }\end{array}$ \\
\hline $\begin{array}{l}\text { Helecbosa de los } \\
\text { Montes }\end{array}$ & $\begin{array}{l}\text { Ermita de la Nazarena } \\
\text { Parroquia }\end{array}$ & $\begin{array}{l}\text { Interior totalmente destruido } \\
\text { Interior totalmente destruido }\end{array}$ & $\begin{array}{l}\text { Almacen de gra- } \\
\text { nos y aceites }\end{array}$ \\
\hline $\begin{array}{l}\text { Bohonal (anejo a } \\
\text { Helecbosa) }\end{array}$ & Parroquia & Interior totalmente destruido & $\begin{array}{l}\text { Vivienda de refu- } \\
\text { giados }\end{array}$ \\
\hline $\begin{array}{l}\text { Herrera del Du- } \\
\text { que }\end{array}$ & Parroquia & Interior totalmente destruido & \\
\hline Peloche & $\begin{array}{l}\text { Emita de la Consolación } \\
\text { Parroquia }\end{array}$ & $\begin{array}{l}\text { Interior totalmente destruido } \\
\text { Interior totalmente destruido }\end{array}$ & $\begin{array}{l}\text { Almacen de vive- } \\
\text { res y matadero }\end{array}$ \\
\hline \multirow[t]{2}{*}{ Peilakordo } & Parroquia & Interior totalmente destruido & $\begin{array}{l}\text { Cárcel y vivienda } \\
\text { de refugiados }\end{array}$ \\
\hline & Ermita del Santo Cristo & Totalmente destruido & $\begin{array}{l}\text { Cárcel y viviends } \\
\text { de refugiados }\end{array}$ \\
\hline \multirow[t]{2}{*}{ Puebla de Alcocer } & Parroquia & Interior totalmente destruido & $\begin{array}{l}\text { Casa del Pueblo, } \\
\text { vivienda de refu- } \\
\text { giados y Cuartel } \\
\text { de milicias. }\end{array}$ \\
\hline & $\begin{array}{l}\text { Convento de Concepcio- } \\
\text { nistas Franciscanas }\end{array}$ & Interior totalmente destruido & \\
\hline Risco & Parroquia & Interior totalmente destruido & Casa del Pueblo \\
\hline
\end{tabular}




\begin{tabular}{|c|c|c|c|}
\hline LOCALIDAD & EDIFICIOS RELIGIOSOS & PÉRDIDAS SUFRIDAS & USO POSTERIOR \\
\hline \multirow[t]{3}{*}{ Struela } & Parroquia & Interior totalmente destruido & $\begin{array}{l}\text { Almacen de mate- } \\
\text { riales de construc- } \\
\text { ción }\end{array}$ \\
\hline & $\begin{array}{l}\text { Capilla del Calvario } \\
\text { Convento de Franciscanas }\end{array}$ & $\begin{array}{l}\text { Interior totalmente destruido } \\
\text { Interior totalmente destruido }\end{array}$ & Taller mecánico \\
\hline & $\begin{array}{l}\text { Eimita de Ntra.Sra. de Alta- } \\
\text { gracia }\end{array}$ & Interior totalmente destruido & Hospital \\
\hline \multirow[t]{2}{*}{ Talarrubiss } & Parroquia & Interior totalmente destruido & \\
\hline & $\begin{array}{l}\text { Capilla del Carmen } \\
\text { Colegio de Religiosas } \\
3 \text { ermitas }\end{array}$ & $\begin{array}{l}\text { Interior totalmente destruido } \\
\text { Interior totalmente destruido } \\
\text { Interior totalmente destruido }\end{array}$ & \\
\hline Tamurejo & Parroquia & Interior totalmente destruido & \\
\hline Valdecaballeros & Parroquia & Interior totalmente destruido & \\
\hline \multirow{2}{*}{$\begin{array}{l}\text { Villarta de los } \\
\text { Montes }\end{array}$} & Parroguia & Interior totsimente destruido & Cároel, almacen... \\
\hline & Ermita de la Antigua & Interior totalmente destruido & \\
\hline Zarza Capilla & Parroxuia & Interior totalmente destruido & Hospital \\
\hline
\end{tabular}

\section{CONCLuSIÓN.}

Parece posible señalar tres modelos seguidos por la persecución religiosa según las comarcas:

Zonas donde estos hechos fueron algo episodico y, en general, se limitaron a incautar los edificios religiosos y a destinarlos a otros usos.

Comarcas en las que predominaron, junto a lo anterior, las iglesias parcialmente saqueadas y destruidas y muertes esporádicas de eclesiásticos.

Zonas donde la persecución se desarrolló de forma sistemática incluyendo templos cuyo contenido fue totalmente destruido y el asesinato de eclesiásticos en casi todas las localidades.

El caso que hemos analizado, la comarca extremeña de Los Montes, entraría claramente dentro de este último modelo de comportamiento caracterizado en nuestro caso por:

- El asesinato de 11 sacerdotes de un total de 21 residentes en la comarca $(52,3 \%)$.

La Iglesia en la Encrucijada

Hispania Sacra 49 (1997) 
- El encarcelamiento de 13 de ellos.

- La expulsión de las comunidades religiosas de sus conventos.

- La proscripción del culto.

- La destrucción sistemática del contenido de unos $\mathbf{4 0}$ templos y ermitas

Por último, únicamente baste expresar nuestro deseo de que estas líneas de investigación por las que estamos orientando nuestros trabajos acerca de la persecución religiosa en España hagan ver la necesidad de una sistematización y tratamiento global de los datos disponibles y sirvan para dar respuesta cabal, acorde con las exigencias inherentes al rigor histórico, a la petición que hacía Juan Pablo II en su Carta Apostólica "Tertio Millennio Adveniente":

«...en nuestro siglo han vuelto los mártires, con frecuencia desconocidos, casi "milites ignoti" de la gran causa de Dios. En la medida de lo posible, no debe perderse en la Iglesia su testimonio. Como se ha sugerido en el consistorio, es preciso que las Iglesias locales hagan todo lo posible por no perder el recuerdo de quienes han sufrido el martirio, recogiendo para ello la documentación necesaria... ( $\left.n^{\circ} 37\right)$.» 